\title{
GROUP DECISION MAKING APPLIED TO PREVENTIVE MAINTENANCE SYSTEMS
}

\author{
José Luis Zanazzi ${ }^{1 *}$, Luiz Flávio Autran Monteiro Gomes ${ }^{2}$ \\ and Magdalena Dimitroff ${ }^{3}$
}

Received February 26, 2013 / Accepted February 28, 2014

\begin{abstract}
This paper describes an application in group decision making, aimed at developing a procedure to help define priorities in preventive maintenance activities. The method applied is called DRV Processes (Decision with Reduction of Variability) and it combines both statistical techniques and multicriteria decision aid procedures. Among its advantages, we may highlight the possibility of reducing the noise affecting information in group decision making and of reaching a consensual decision. This approach generally improves the level of shared knowledge and helps to avoid conflict within the group. The application was carried out in a major pharmaceutical production plant. The experience showed an eighty per cent reduction in the original amount of process noise. Moreover, the paper describes evidence of improvement in interpersonal relationships.
\end{abstract}

Keywords: Preventive Maintenance Systems, Group Decision Making, DRV Processes.

\section{INTRODUCTION}

Modern organizations require people to work in small teams to reach consensual decisions. What is more, group analysis of decision-related issues is deemed desirable at strategic, tactical and operational levels. For example, in the model called Lean Production, or Lean Organization, the organization is structured in small groups named cells, and the responsibility for decisions is generally transferred to these cells. See Angelis et al. (2011); Wilson \& Roy (2009); Chowdary \& George (2012).

One of the issues to be analyzed by working teams is the selection and management of proper maintenance systems for the means or assets involved in manufacturing. For these systems, it

\footnotetext{
*Corresponding author

${ }^{1}$ LIMI-FCEFyN - Universidad Nacional de Córdoba, Avda. Vélez Sarsfield 1611, Córdoba, Argentina.

-E-mail: jl.zanazzi@gmail.com

${ }^{2}$ Ibmec/RJ - Av. Presidente Wilson, 118, Room 1110, 20030-020 Rio de Janeiro, RJ, Brazil. E-mail: autran @ibmecrj.br

${ }^{3}$ LIMI-FCEFyN - Universidad Nacional de Córdoba, Avda. Vélez Sarsfield 1611, Córdoba, Argentina.

-E-mail: magdadimitroff@gmail.com
} 
is necessary to determine levels of criticality that result in an order for development and the establishment of priorities for actions (Rausand, 1998). It is obviously desirable to reach a certain consensus regarding those priorities.

There is a variety of approaches to the selection of the most convenient maintenance method. Some of the available resources are: Multi-Criteria Decision Methods (MCDM); Fuzzy Sets; Rough Set Theory; Neural Networks; Goal Programming (Bevilacqua \& Braglia, 2000; Bertolini \& Bevilacqua, 2006; Arunraj \& Maiti, 2010). Levels of criticality are also determined by using variations of the Failure Modes and Effects Analysis (FMEA) Alencar et al. (2012), Chen (2013). Generally, such criticalities are individually established, without explicitly taking into account potential differences between persons or areas interested in the problem.

However, the design and implementation of maintenance management systems becomes a complex problem, involving material, economic, social and individual aspects (Vidal, 2006). Thus, a successful implementation requires that the opinions of the various actors be taken into account, usually in a context of uncertainty and incomplete and inaccurate data (Mingers \& Rosenhead, 2004).

This study describes the case of a large pharmaceutical manufacturing company in which at least two previous attempts at implementation of a maintenance management system had failed for a variety of reasons. An important element was the lack of agreement among the groups in charge of manufacturing, quality and maintenance.

Taking those precedents into account, it was decided to carry out the determination of the levels of criticality as an exercise in group decision making, performed by a group of fifteen persons with leadership roles in those three areas. Predictably, at the start of the analysis process, the differences among group members generated a high noise level that affected the data (uncertainty, inaccuracy and even lack of information).

In this context, it was decided to apply the method known as DRV Processes (Decision with Reduction of Variability), proposed by Zanazzi \& Gomes (2009), Zanazzi et al. (2006). A key assumption of this method, provided that goals are shared by the group, is that in group decision making it becomes feasible to reduce the noise level to a minimum, which leads to an improvement of the team work.

As a result, the paper proposes contributions in two areas. First, a method for the determination of the levels of criticality by working groups, which facilitates the implementation of a maintenance management system by attaining a certain level of consensus on priorities. As described in section 2.2, this strategy is not frequently employed in maintenance management.

Besides, practical evidence is contributed to prove that, in group decision making, the collaborative analysis aimed at noise reduction can significantly contribute to group initiative and commitment to the actions agreed upon.

The paper is organized as follows. Section 2 reviews assumptions and methods related to the solution of similar problems. Section 3 describes briefly the DRV Processes. Section 4 explains the application and analyzes the results. Finally, Section 5 draws some conclusions and suggests guidelines for further research. 


\section{REVIEW OF PREVIOUS WORK IN THE FIELD}

\subsection{Group decision making methods}

Developers of Group Decision Making (GDM) methodologies have used various approaches. Some have adapted methods originally designed for individual decision making to GDM problems. Other researchers maintain that there is a different paradigm applicable to the GDM process.

For instance, for group applications of the Analytic Hierarchy Process (AHP), Forman \& Peniwati (1998) recommend the use of the geometric mean of the judgments or of the priorities, according to the level of group cohesion, in order to obtain an aggregate valuation. Alencar et al. (2010) propose a method suitable for groups whose members do not share goals. This method uses Electre II to determine the preference of each member and then Electre IV to obtain an aggregate.

The Operative Research Soft (OR Soft) stands out in the second research trend. It includes approaches based on the personal construct theory, such as the Repertory Grid (Alexander et al., 2010), and the method of Strategic Options in Development and Analysis (SODA), with cognitive mapping (Ackermann \& Vreede, 2011). Another important contribution is the Soft System Methodology (Georgiou, 2006), which may be considered a key element in the system concept as applied to strategic planning.

These approaches place special emphasis on the different perceptions of group members and on their interaction. Several authors have found many advantages in these approaches: group learning and contribution to the development and consolidation of an organizational culture (Sorensen \& Vidal, 2003); participative analysis and development of shared knowledge, comprehensive solutions and commitment to the solutions implemented (Kaner et al., 2007; Franco \& Montibeller, 2010).

However, the mentioned authors agree that the OR Soft is suitable for highly complex problems and/or strategic level decisions, since usually these are laborious processes and they span an extended time period.

The premises of the so called Hard methods appear to be opposed to the preceding approaches since they are aimed at reaching a decision swiftly, without necessarily counting on the agreement of the group members. In general, Hard methods assume that, in the real world, differences in opinion or difficulties in information gathering are common issues. A widely used resource for representing this variability in basic information is Fuzzy Sets (Merigó et al., 2011; Lin et al., 2011).

The SMAA (Stochastic Multicriteria Acceptability Analysis) family of methods constitutes another approach. These methods assume that criteria weights are unknown or that there is a complete lack of agreement on them. Consequently, different possible structures of preferences are analyzed and the probabilities of their being true are inferred (Tervonen \& Figueira, 2008).

The VIP (Variable Interdependent Parameters) method involves a different approach, which highlights the importance of specifying and weighting criteria in group decision making processes. 
In fact, proponents of this approach consider that modeling offers a great opportunity for workgroup learning (Dias \& Clímaco, 2005).

Summing up, all methods recognize that there are differences and variations in the perceptions, preferences and values of group members. The Soft approach addresses the analysis of those variations and is only applicable to complex problems. On the other hand, some Hard methods tend to focus on reasonable solutions in the presence of noise.

The contributions that acknowledge the existence of noise and attempt to reduce it do so through various methodological approaches: Evidential Reasoning, Fuzzy Sets, and Multivariate Random Variables. The general trend is to reach a consensus position and to evaluate its distance from the observations contributed by the decision makers, in order to feedback an iterative process.

For instance, Fu \& Yang (2012) propose a sequence of steps, based on Evidential Reasoning, in which group members contribute their judgments by intervals and are able correct their appraisals by comparing them to a consensus model. In group decision making based on AHP, Multivariate Random Variables are used to obtain consensus matrices and Bayesian approximations are used for identification of agreement and disagreement zones (Altuzarra et al., 2010; Escobar \& Moreno-Jimenez, 2007).

\subsection{Maintenance management system}

Since maintenance has a direct impact on productivity, there has been much work done on possible alternative actions aimed at improving both areas. Obviously, the most basic alternative is Failure Maintenance or Corrective Maintenance, i.e. repairing items of equipment when they cease to function properly.

An economically more attractive option is Planned Maintenance, in which actions are scheduled so as to minimally affect production. This approach includes well-known advanced strategies such as Time Based Maintenance (TBM) and Conditions Based Maintenance (CBM).

TBM actions may include checking, replacement or repair of parts or components at regular intervals, even if they are working properly. The existing literature offers many examples of how to determine the best time periods for these actions, based predominantly on criteria of cost or potential economic loss (Damaso \& García, 2009; Almeida, 2012).

CBM, also called Predictive Maintenance, aims at predicting potential failures by early detection through specific technologies of abnormal levels of operation parameters. Vibration analysis provides an instance of the prediction of potential failures in rotating elements, whereas tomography is useful in the prediction of mechanical or electrical anomalies. Several contributions have made these tools known and have analyzed the most commonly used technologies (Jardine et al., 2006; Heng et al., 2009).

A related complementary strategy is Autonomous Preventive Maintenance (APM), which involves equipment operators in primary maintenance responsibilities. Operators assume the obli- 
gation of the necessary and basic care and repair of machines (Chen, 2013). In this case, maintenance includes simple tasks such as cleaning, lubricating, adjusting, and replacing parts.

The problem of choosing the most appropriate maintenance strategy has been dealt with in a variety of specialized contributions. To facilitate the choice, the models of Multiple Criteria Decision Methods (MCDM) have been proposed (Bevilacqua \& Braglia, 2000; Bertolini \& Bevilacqua, 2006; Arunraj \& Maiti, 2010) analyze the problem of convenience, concluding that the choice must take into account the equipment level of criticality and that, for the highest levels of criticality, CBM should be applied.

Maintenance programs that integrate several of the previous options have also been proposed. The best known ones are Total Productive Maintenance (TPM), often acknowledged as being a key component of Lean Production and whose fundamental asset is APM. Another widely known option is Reliability Centered Maintenance (RCM) (Rausand, 1998), which originated in aeronautics and was later disseminated and transferred to various production systems (Moubray, 2001).

Since maintenance activities do not add value to the products, a rational use of the allotted resources is required, in accordance with productivity principles. This implies the necessity of knowing the system needs and of a sensible allocation of tasks, resources, responsibilities and times.

A rational use of the available resources also yields a higher speed of response and quality of service (Kelly, 2006). Hence the need to determine the equipment levels of criticality so as to direct efforts properly.

Furthermore, resources are normally insufficient or barely sufficient for the optimal care of all production means, which makes it necessary to select those having a higher impact, to establish different priorities and to sequence their treatment.

To productivity demands and resource restrictions, it is necessary to add complex scenarios in organization management which force the setting of priorities. Market uncertainties, production volumes, product mix, frequency of changes, processing capacity, and labor skills are some factors in permanent interaction and over which companies cannot achieve complete control (Mazini et al., 2010).

Determination of levels of criticality may be done by item of equipment or by type of failure. Some of the best known tools in use are the Failure Modes and Effects Analysis (FMEA), which may be considered a multi-criteria approach, and the Root-Cause Analysis (RCA), which proposes a systematic search for the root cause of each type of failure.

To the approaches mentioned previously, various improvements have been proposed that take into consideration the economic effects of failures. For instance, Braglia (2000) postulates a multi-criteria decision model based on AHP that gives particular consideration to the economic effects of failure. Additionally, Alencar et al. (2012) suggest an MCDM model that employs the usual occurrence and detectability criteria, with the addition of resulting losses, including casu- 
alties, financial costs and lack of availability of production equipment. Chen (2013) combines the FMEA and RCA approaches in a method that takes into consideration the role of equipment in productivity and reduction of manufacturing costs.

Overall, there is a wide range of proposed approaches that facilitate the choice of the most appropriate maintenance strategy. Yet, their main flaw is that they are based on a single and individual point of view. Thus, they take into consideration neither the superficial nor the deep differences in the interests and perceptions of the persons or areas involved in maintenance. Nevertheless, such differences are to be expected in every organization, and may impair the success of any management system.

\section{DESCRIPTION OF DRV PROCESSES}

DRV processes have been developed to support Group Decision Making (GDM), according to Kersten (1997), Escobar \& Moreno-Jiménez (2007). They are applicable to the cases in which all members of the group operate in the same organization and, therefore, they must share organizational values, knowledge and preferences. The DRV assumes that it is necessary to generate agreement on the preferences of group members.

\subsection{Stages of the Method}

The group is expected to structure the decision-making problem and to represent it by using a depiction means, such as a tree diagram. The problem may be divided into sub-problems so as to contrast different criteria, compare alternatives against each criterion and so on.

The process of analysis is divided in stages: stabilization, aggregation and ranking. The stabilization stage is iterative. For each sub-problem, exercises aim at a better understanding and at the exchange of knowledge and opinions. Once the analysis is deemed sufficient, participants assign priorities to the elements being compared, using a subjective-type utility function. To perform this task, each group member works with total independence of the others.

Stabilization is verified using the normality analysis of priorities for each element of a subproblem, or by using the IVR (Índice de Variabilidad Remanente, Remaining Variability Index) indicator, according to Zanazzi \& Gomes (2009), which can be computed using expression (1):

$$
I V R=\frac{S S W}{S C U} * 100 \%
$$

where $S S W$ (Sum of Squares Within) represents the residual variability after a stage of analysis. $S C U$ corresponds to the uniform distribution and reflects a situation of complete disagreement within the group. It may normally be assumed that $I V R$ values under $25 \%$ are indicative of stability.

The process ends when the analysis yields no further variation in individual priorities. At this point, the analysis process is assumed to have reached a stable condition. 
Once all the processes have been stabilized, the aggregation stage leads to calculation of a sample of global valuations for each alternative. This may be carried out using Linear Weighting or the expressions of the TODIM method (Gomes \& Rangel, 2009), as described in section 3.1.

For the third stage, i.e. ranking, global valuations are used. Repeated hypothesis testing is used to determine whether the differences found in the aggregation stage may be considered indicative of actual preference differences or may have been obtained by chance.

In the ranking stage, samples are analyzed to define the ordering of the alternatives by applying comparison hypothesis testing of dependent variable means. Besides, the method uses an algorithm (Benjamini \& Yekutieli, 2001) to control Type I error probability.

\subsection{Multivariate Random Model of DRV Processes}

Once a stable condition is reached for a given sub-problem, the method assumes that the priorities established by group members must have a random behavior, represented by Normal Distribution. Under this assumption, let $X_{k}$ be a random variable that represents the priorities assigned to element number $k$ of the sub-problem in the stable condition. When group members set their values, for each element in each sub-problem (criteria or alternatives), they assign higher or lower priorities to each item, taking into account a large number of effects,

$$
X_{k}=\sum_{i=1}^{L} Y_{i}
$$

where $Y_{i}$ represents the multiple influences on the assignments.

These multiple influences are related to individual perceptions and values. In other words, they depend on previous experiences, personal history, personal interests, and individual subjectivity, among others.

If all influences have a similar impact, according to the Central Limit Theorem $X_{k}$ should be normally distributed $N\left(\mu_{k}, \sigma_{k}^{2}\right)$. The reasoning previously expressed in (2), may be considered valid for the weights of the criteria and the priorities of the alternatives.

Once all sub-problems have been stabilized, it is possible to determine global values for each alternative. To do so, there are two possibilities: linear weighting or the TODIM method.

In the first case, if $W_{j}$ represents the criteria weights and $U_{i j}$ represents the utilities assigned to the alternative number $i$ under criterion $j$, then the partial contribution to the priority assigned to a generic alternative $i$, under criterion $j$ is obtained as the product of both random variables, as expressed in (3).

$$
Z_{i j}=W_{j} * U_{i j}
$$

Therefore, the probability density function of the random variable $\left(W_{j}, U_{i j}\right)$ is given by the expression (4).

$$
f_{\left(W_{j}, U_{i j}\right)}\left(w_{j}, u_{i j}\right)=\frac{1}{2 \pi} \frac{1}{\sigma_{W_{j}} \sigma_{U_{i j}}} e^{-\frac{1}{2}\left(\frac{w_{j}-\mu_{W_{j}}}{\sigma_{W_{j}}}\right)^{2}} e^{-\frac{1}{2}\left(\frac{u_{i j}-\mu_{U_{i j}}}{{ }^{\sigma_{U_{i j}}}}\right)^{2}}
$$


Then, the probability distribution function of $Z_{i j}$ can be formulated as expressed in (5).

$$
P\left(W_{j} * U_{i j}<z\right)=\iint_{(w, u) \in\left\{W_{j} * U_{i j}<z\right\}} \frac{1}{2 \pi} \frac{1}{\sigma_{W_{j}} \sigma_{U_{i j}}} e^{-\frac{1}{2}\left(\frac{w-\mu_{W_{j}}}{\sigma_{W_{j}}}\right)^{2}} e^{-\frac{1}{2}\left(\frac{u-\mu_{U_{i j}}}{\sigma_{U_{i j}}}\right)^{2}} d w d u
$$

Although this last integral cannot be analytically solved, it is possible to represent it by using a Normal Distribution, according to Zanazzi \& Gomes (2009). The parameters of these distributions can be obtained with expressions (6) and (7).

$$
\begin{gathered}
E\left(Z_{i j}\right)=E\left(W_{j}\right) * E\left(U_{i j}\right)=\mu_{i j} \\
\operatorname{Var}\left(Z_{i j}\right)=\left(E^{2}\left(W_{j}\right)+\operatorname{Var}\left(W_{j}\right)\right) *\left(E^{2}\left(U_{i j}\right)+\operatorname{Var}\left(U_{i j}\right)\right)-E^{2}\left(W_{j}\right) * E^{2}\left(U_{i j}\right)=\sigma_{i j}^{2}
\end{gathered}
$$

Following this assumption, the global weight of the generic alternative $\left(V_{i}\right)$ is also Normal and can be expressed as follows:

$$
V_{i}=\sum_{j=1}^{J} W_{j} * U_{i j}=\sum_{j=1}^{J} Z_{i j}
$$

As said above, another possibility is to apply the expressions of the TODIM method. This approach applies the concepts of Prospect Theory, according to Kahneman \& Tversky (1979).

In this case, one criterion is taken as reference (criterion $r$ ) and substitution rates for the other criteria are worked out:

$$
a_{r j}=\frac{\mu_{W_{j}}}{\mu_{W_{r}}}
$$

The partial dominance matrices and a final dominance matrix are calculated. Partial dominance of alternative $i$ over another alternative $m$, under criterion $j$, is obtained by (10).

$$
\delta(i, m)=\sum_{j=1}^{J} \Phi(i, m) \quad \forall 1 \leq i \leq I, \quad 1 \leq m \leq I
$$

where $\Phi(i, m)$ represents the partial contribution of criterion $j$ to function $\delta(i, m)$, i.e., the global change obtained by substituting alternative number $m$ by alternative number $i$, considering criterion $j$.

If the mean for alternative $i$ is greater than the mean for alternative $m$, there is a gain. Otherwise, there is a loss. This can be worked out as expressed in (11), (12) and (13).

$$
\begin{aligned}
& \Phi(i, m)=0 \quad \forall i=m \\
& \Phi(i, m)=\left(a_{r j}\left(U_{i j}-U_{m j}\right): \sum_{j=1}^{J} a_{r j}\right)^{1 / 2} \text { where there is gain } \\
& \Phi(i, m)=-\frac{1}{\theta}\left(\left(\sum_{j=1}^{J} a_{r j}\right)\left(U_{i j}-U_{m j}\right): a_{r j}\right)^{1 / 2} \quad \text { where there is loss }
\end{aligned}
$$


In this way, the global dominance of alternative number $i$, is obtained by the sum of partial dominances as expressed in (14), which represents the total result of choosing alternative number $i$ and omitting the others.

$$
v_{i}=\sum_{m=1}^{I} \delta(i, m)
$$

\section{DESIGN OF A PREVENTIVE MAINTENANCE SYSTEM}

The method was applied to an important pharmaceutical manufacturing plant. Its management was interested in the design and implementation of a preventive maintenance control system which would take into account the needs of all the departments involved: Maintenance, Quality and Production.

There were many differences of opinion between the areas, particularly between the engineers and technicians in the Maintenance department, and the chemists and biochemists in the other departments. There was even some evidence of previous conflict among the group members.

The first step consisted of a training activity on maintenance systems, which evinced the need to develop a framework that would allow groups to set priorities in the preventive system. Interdisciplinary groups were formed to analyze particular processes. Then a plenary session was held, in which operations were described and knowledge and experiences were shared. This constituted a very enriching experience.

The next step was the selection of a consensual method for establishing levels of criticality for each item of equipment and type of failure. The group adopted the criteria shown in Table 1 and drafted appropriate definitions for each criterion, aimed at clarifying what should be understood as impact on the product, on the process, and so on.

Table 1 - Definition of criteria used to decide on criticality.

\begin{tabular}{|c|c|}
\hline Order & Criteria \\
\hline 1 & Impact on product \\
2 & Impact on process \\
3 & Maintainability \\
4 & Failure Frequency \\
5 & Impact on Environment and Security \\
\hline
\end{tabular}

It should be noted that rather few criteria were adopted and that they were not substantially different from those used in the usual version of FMEA. Specifically, after giving it due consideration, participants in the exercise decided not to include the possibility of detection as a criterion. At any rate, it is important to point out that team work fostered the exchange of perceptions and knowledge. 


\subsection{Criteria Weighting}

Criteria weighting is crucial when determining the criticality level for each failure mode. If group members participate actively in assigning priorities, they are more likely to support those priorities afterwards.

During the plenary session, the group appeared to reach a reasonable agreement. To verify this, DRV Processes require individual weightings. If there is no cohesion, the assigned utilities may be represented by a uniform distribution whose mean is equal to the inverse number of elements compared, in which case the expected sum of squares within is 0,933 .

In this case, at the end of the first cycle of analysis, the IVR indicator was 0,5774. Since this value was high, it was necessary to restart discussions particularly on those aspects where discrepancies appeared to be greater.

It should be remembered that there had been much previous team work and that an agreement appeared to have been reached. Yet, there are often differences that do not surface in the plenary sessions and that are only revealed in the individual assignation of priorities.

At the end of the second cycle of analysis, the IVR amounted to 22,62\%, which was considered acceptable, since it showed an important reduction in the differences previously found between decision makers.

It is interesting to analyze the variation of results in this sub-problem. Table 2 shows IVR values and parameter values obtained in both assessments. It can be seen that these values are different, particularly for the Product criteria.

Table 3 shows the Sums of Squares for the initial condition and for both subsequent weightings.

Table 2 - Parameters obtained and IVR Index.

\begin{tabular}{|c|c|c|}
\hline \multirow{2}{*}{} & \multicolumn{2}{|c|}{ Weighting } \\
\cline { 2 - 3 } & First & Second \\
\hline Product & 0,5826 & 0,4653 \\
Process & 0,2008 & 0,2263 \\
Maintainability & 0,089 & 0,1288 \\
Failure Frequency & 0,073 & 0,1055 \\
Environment \& Security & 0,0546 & 0,074 \\
IVR & 0,5774 & 0,2262 \\
\hline
\end{tabular}

Table 3 - Evolution of Sum of Squares Within.

\begin{tabular}{|c|c|c|}
\hline Cycle & Sum of Squares Within & Original percentage IVR \\
\hline 0 & 0,933 & $100,0 \%$ \\
1 & 0,539 & $57,7 \%$ \\
2 & 0,211 & $22,6 \%$ \\
\hline
\end{tabular}


Table 3 results show the feasibility of effectively reducing the noise affecting information. If we assume that the Sum of the Squares Within (SSW) represents such noise, two analysis cycles have sufficed to achieve a reduction in the original variability to slightly over twenty per cent.

\subsection{Failure Mode Weighting}

Once criteria had been established and weights had been assigned, the whole group carried out two exercises in which the failure modes were compared, with the purpose of arriving at a shared interpretation.

Table 4 summarizes the failure modes for the various items of equipment that were compared in one of those exercises.

A preliminary ranking may be obtained by placing averages as shown on Table 5.

Due to the inaccuracies that may affect observations, some of these differences may only be apparent. To clarify this, DRV Processes apply repeatedly a comparison hypothesis test of dependent variable means. This rendered the results shown in Table 6.

Table 4 - Equipment and failure modes.

\begin{tabular}{|c|c|c|c|}
\hline Code & Equipment & Component & Failure Mode \\
\hline A1 & Ice Bench & Electric Control Switch Board & Broken PLC \\
A2 & Ice bench & Electric pump & Broken Seal \\
A3 & Bottler & Feeding tube & Cut tube \\
A4 & Bottler & Nitrogen tube & Choked tube \\
A5 & Big Autoclave & Ducts & Punctured ducts \\
A6 & Big Autoclave & Pressure gauge & Broken gauge \\
\hline
\end{tabular}

Table 5 - Global values alternatives and averages.

\begin{tabular}{|c|c|c|c|c|c|}
\hline A1 & A3 & A5 & A2 & A6 & A4 \\
\hline 0,312 & 0,189 & 0,181 & 0,123 & 0,116 & 0,079 \\
\hline
\end{tabular}

Table 6 - Mean comparison Test Results.

\begin{tabular}{|c|c|c|c|c|c|}
\hline Difference & A1-A3 & A3-A5 & A5-A2 & A2-A6 & A6-A4 \\
\hline$p$-value & $5,78 \mathrm{E}-12$ & 0,12928 & $2,59 \mathrm{E}-08$ & 0,199078 & $5,62 \mathrm{E}-08$ \\
\hline
\end{tabular}

In this case, we do not reject the null hypothesis for the differences between A5 and A3, on the one hand, and between A2 and A6, on the other. Therefore, the following preliminary ranking can be proposed: $\mathrm{A} 1>\mathrm{A} 3=\mathrm{A} 5>\mathrm{A} 2=\mathrm{A} 6>\mathrm{A} 4$.

This experience resulted in a collaborative drafting of a scale for judgment assignment within each criterion. Each element in the guide has a score ranging from 1 to 9, and an explanation of the conditions under which such score must be assigned. 
Following this, some participants proceeded to identify and assign values to the failure modes of the plant equipment. It was agreed to take, as an indicator of criticality levels, the sum of scores of the three failure modes with the highest absolute criticality. Thus, the global valuations shown in Table 7 were obtained.

Table 7 - Equipment criticality indicators.

\begin{tabular}{|c|c|}
\hline Equipment & Indicator Criticality \\
\hline Pasteurizer & 77,8 \\
Autoclave 001 & 65,7 \\
Heater & 43,7 \\
Autoclave 003 & 39,5 \\
Washing machine & 24,4 \\
\hline
\end{tabular}

It is important to note that, besides enabling the assignation of priority levels to failure types, the experience was interesting because it allowed group members to have a shared vision of the problem, to exchange ideas and knowledge and thus to become committed to the decisions made. As a result, communication among group members was improved and favorable conditions were created for the implementation of a preventive maintenance management system.

\section{CONCLUSIONS}

The first stage in the implementation of a preventive maintenance management system in a pharmaceutical production plant has been described. In this case, the challenge was to reduce the differences among the relevant departments, which had prevented such implementation before.

To overcome this difficulty, the group was asked to develop a reference framework that would help in setting maintenance priorities. Instead of establishing those priorities using FMEA, RCA, or other suitable method, the collaborative building of an analysis tool was considered preferable.

This group exercise facilitated the Exchange of opinions, experiences, and knowledge. Each group member had a chance to know the points of view of the other members. Results were positive, the system was implemented and interpersonal relations were improved.

As discussed above, when a group analyzes a decision to be made, differences among group members are likely to arise. Such differences may become noise that distorts the available information. By applying DRV processes, such noise can be turned into an opportunity for improvement and the ensuing analysis can lead to significant noise reduction, commitment to decisions, and advances in the group's shared knowledge.

This experience made it possible to reduce the original noise level values affecting the process to slightly more than $20 \%$. Moreover, following the experience group relations improved significantly and the maintenance system is currently in full development as a joint project of the areas involved. 
Additionally, the experience described here and other similar ones foster an optimistic view on the possibilities of noise reduction available in DRV processes. However, further generalization of the proposal and more checks on the process are necessary.

\section{ACKNOWLEDGMENTS}

The research on which this paper is based was partially financed by the Brazilian National Council for Scientific and Technological Development (CNPq), through Process N. 310603/2009-9.

\section{REFERENCES}

[1] Ackermann F \& VReede G. 2011. Special Issue on 'Advances in Designing Group Decision and Negotiation Processes'. Group Decision and Negotiation, 20(3): 271-272.

[2] Alencar LH, Almeida ATD \& Morais DC. 2010. A multicriteria group decision model aggregating the preferences of decision-makers based on ELECTRE methods. Pesquisa Operacional, 30(3): $687-702$.

[3] Alencar LH, de Almeida Filho AT \& de Almeida AT. 2012. FMECA: modelagem multicritério para priorização de causas de falhas potenciais em uma termoelétrica. 2012 SOBRAPO Annals XVI CLAIO - XLIV SBPO - Workshop LIA-SGT - Rio de Janeiro, RJ Available online in <http: / /www.din.uem.br/sbpo/sbpo2012/pdf/arq0183.pdf>.

[4] Alexander P, van Loggerenberg J, Lotriet H \& Phahlamohlaka J. 2010. The Use of the Repertory Grid for Collaboration and Reflection in a Research Context. Group Decision and Negotiation, 19(5): 479-504.

[5] Almeida AT. 2012. Multicriteria Model for Selection of Preventive Maintenance Intervals. Quality and Reliability Engineering International, 28(6): 585-593.

[6] Altuzarra A, Moreno-Jiménez JM \& Salvador M. 2010. Consensus building in AHP-group decision making: a Bayesian approach. Operations research, 58(6): 1755-1773.

[7] Angelis J, Conti R, Cooper G \& Gill C. 2011. Building a high-commitment lean culture. Journal of Manufacturing Technology Management, 22(5): 569-586.

[8] ARUnRAJ NS \& MAITI J. 2010. Risk-based maintenance policy selection using AHP and goal programming. Safety Science, 48(2): 238-247.

[9] Benjamini Y \& Yekutieli D. 2001. The control of the false discovery rate in multiple testing under dependency. The Annals of Statistics, 29(4): 1165-1188.

[10] Bertolini M \& BeVilacQua M. 2006. A combined goal programming - AHP approach to maintenance selection problem. Reliability Engineering \& System Safety, 91(7): 839-848.

[11] Bevilacqua M \& BRaglia M. 2000. The analytic hierarchy process applied to maintenance strategy selection. Reliability Engineering \& System Safety, 70(1): 71-83.

[12] BRAgLiA M. 2000. MAFMA: multi-attribute failure mode analysis. International Journal of Quality \& Reliability Management, 17(9): 1017-1033.

[13] CHEN CC. 2013. A developed autonomous preventive maintenance programme using RCA and FMEA. International Journal of Production Research, (ahead-of-print), 1-9. 
[14] ChOWdary B \& GeORGE D. 2012. Improvement of manufacturing operations at a pharmaceutical company: a lean manufacturing approach. Journal of Manufacturing Technology Management, 23(1): 56-75.

[15] DAMASO VC \& GARCIA PADA. 2009. Testing and preventive maintenance scheduling optimization for aging systems modeled by generalized renewal process. Pesquisa Operacional, 29(3): 563-576.

[16] Dias L \& CLÍmACo J. 2005. Dealing with imprecise information in group multicriteria decisions: a methodology and a GDSS architecture. European Journal of Operational Research, 160: 291-307.

[17] Escobar MT \& Moreno-Jiménez JM. 2007. Aggregation of individual preference structures in AHP-group decision making. Group Decision and Negotiation, 16(4): 287-301.

[18] Forman E \& Peniwati K. 1998. Aggregating individual judgments and priorities with the analytic hierarchy process. European Journal of Operational Research, 108: 165-169.

[19] Franco L \& Montibeller G. 2010. Facilitated modelling in operational research. European Journal of Operational Research, 205: 489-500.

[20] Fu C \& YANG S. 2012. An evidential reasoning based consensus model for multiple attribute group decision analysis problems with interval-valued group consensus requirements. European Journal of Operational Research, 223(1): 167-176.

[21] Georgiou I. 2006. Managerial Effectiveness from a System Theoretical Point of View. Systemic Practice and Action Research, 19(5): 441-459.

[22] Gomes LFAM \& RAngel LAD. 2009. An application of the TODIM method to the multi-criteria rental evaluation of residential properties. European Journal of Operational Research, 193: 204-211.

[23] Heng A, Zhang S, Tan AC \& Mathew J. 2009. Rotating machinery prognostics: State of the art, challenges and opportunities. Mechanical Systems and Signal Processing, 23(3): 724-739.

[24] JARDINE AK, Lin D \& BANJEVIC D. 2006. A review on machinery diagnostics and prognostics implementing condition-based maintenance. Mechanical systems and signal processing, 20(7): 14831510 .

[25] Kahneman D \& TVersky A. 1979. Prospect Theory: an analysis of decision under risk. Econometrica, 47(2): 262-291.

[26] Kaner S, Lind L, Toldi C, Fisk S \& Berger D. 2007. Facilitator's guide to participatory decision-making (2nd ed.). San Francisco: Jossey-Bass.

[27] Kelly A. 2006. Managing Maintenance Resources. Butterworth-Heinemann, Oxford, UK.

[28] Kersten G. 1997. Support for Group Decision and Negotiations. An Overview. In: Multicriteria Analysis [edited by J. Clímaco], Heilderberg, Springer Verlag, 332-346.

[29] Lin L, HuAng L \& YeH H. 2011. Fuzzy Group Decision-Making for Service Innovations in Quality Function Deployment. Group Decision and Negotiation. <http: / / dx . doi . org/10 . 1007 / s10726-010-9223-5>:1-23.

[30] Manzini R, Regattieri A, Pham H \& Ferrari E. 2010. Maintenance for Industrial Systems. Springer-Verlag London.

[31] Merigó JM, Gil-Lafuente AM, Zhou L \& Chen H. 2011. Generalization of the linguistic aggregation operator and its application in decision making. Journal of Systems Engineering and Electronics, 22(4): 593-603. Available online at www . j seepub . com 
[32] Moubray J. 2001. RCM II: reliability-centered maintenance. Industrial Press Inc.

[33] Mingers J \& Rosenhead J. 2004. Problem structuring methods in action. European Journal of Operational Research, 152(3): 530-554.

[34] Tervonen T \& FigueIRA JR. 2008. A survey on stochastic multicriteria acceptability analysis methods. Journal of Multi-Criteria Decision Analysis, 15: 1-14.

[35] Rausand M. 1998. Reliability centered maintenance. Reliability Engineering \& System Safety, 60(2): 121-132.

[36] Sorensen L \& Vidal RVV. 2003. The Anatomy of Soft Approaches. Pesquisa Operacional, 24(2): 173-188.

[37] VIDAL RVV. 2006. Operational research: a multidisciplinary field. Pesquisa Operacional, 26(1): 69-90.

[38] Wilson M \& Roy R. 2009. Enabling lean procurement: a consolidation model for small- and medium-sized enterprises. Journal of Manufacturing Technology Management, 20(6): 817-833.

[39] Zanazzi JL, Carignano C, Boaglio L, Dimitroff M \& Conforte J. 2006. Metodología para apoyar la toma de decisiones en equipo. Revista de la Escuela de Perfeccionamiento en Investigación Operativa, 27: 61-74.

[40] ZanazZI JL \& Gomes LFAM. 2009. La búsqueda de acuerdos en equipos de trabajo: el método Decisión con Reducción de la Variabilidad (DRV). Pesquisa Operacional, 29(1): 195-221. 